\title{
"Some Unholy Alloy": Neoliberalism, Digital Modernity, and the Mechanics of Globalized Capital in Cormac McCarthy's The Counselor
}

David Deacon

\section{OpenEdition}

\section{Journals}

Electronic version

URL: https://journals.openedition.org/ejas/12364

DOI: $10.4000 /$ ejas. 12364

ISSN: 1991-9336

Publisher

European Association for American Studies

Electronic reference

David Deacon, "'Some Unholy Alloy": Neoliberalism, Digital Modernity, and the Mechanics of Globalized Capital in Cormac McCarthy's The Counselor", European journal of American studies [Online], 12-3 | 2017, Online since 12 December 2017, connection on 08 July 2021. URL: http://journals.openedition.org/ ejas/12364 ; DOI: https://doi.org/10.4000/ejas.12364

This text was automatically generated on 8 July 2021 .

Creative Commons License 


\title{
"Some Unholy Alloy": Neoliberalism, Digital Modernity, and the Mechanics of Globalized Capital in Cormac McCarthy's The Counselor
}

\author{
David Deacon
}

Cormac McCarthy's fiction has explored the realm of commerce, capital, and its role in sublimating and/or compounding violence in the United States (and its borderlands), from the inception of its mythos (Blood Meridian) through to its symbolic dissolution (The Road). Value systems, their origins, or radical contingency, have long been a source of intrigue as McCarthy's protagonists either embark upon, or are the victims of some larger animating force. I will argue that The Counselor makes the mutual enterprise of commerce and nefarious criminal activity visible, and as such invites a reading of the protagonist as an agent between such forces of good and evil. The role of hero is complicated by an intrinsic link between this sense of agency, and an implicit criminality and victimhood. Lydia R. Cooper, when considering the role of such a primary agent and the moral weight of their decisions, asserts that "[a] complex dialectic between despair and idealism runs through McCarthy's corpus" (1). This dialectic proves to be more labyrinthine with the evolution of McCarthy's work, and crucially as he attempts to capture the conditions of heroism, agency, and tragedy under globalized digital modernity-or the circumstances of neoliberalism. The Counselor is relatively unique in McCarthy's canon in that it makes tangible the violent commerce of cross-border trade, often taking the form of (unethical) human traffic, while tying it directly to a globalized network of beneficiaries through what Dan Schiller has called "digital capitalism." ${ }^{1}$ By investigating the appearance of globalized capital with reference to Schiller I will argue that it not only serves to fortify the violent enterprise of commodity exchange, but also presents the increasingly 
ephemeral nature of accountability in direct proportion to the fluidity of global trade and domination through capital (represented by Malkina).

2 Jonathan Elmore and Rick Elmore state that No Country for Old Men (2005) posits the emergence of Homo Economicus as a “'new' type of human being, one frighteningly devoid of any recognizable humanity, yet one that remains reasonable, principled, and calculating" (169). Anton Chigurh in the novel is symbolic of the emergent terror such an ideology represents and visits upon populations, to the extent that he is deemed a "true and living prophet of destruction" (5) by the narrator Sheriff Tom Bell. Chigurh's professions about potential and inevitable victims of the philosophy he represents renders the sufferers merely victims of fate and natural order, as opposed to choice or emancipatory agency. As Elmore and Elmore aver, Chigurh's words to Carla Jean near the conclusion of the novel attest to this: "The shape is drawn. No line can be erased. I had no belief in your ability to move a coin to your bidding. How could you? A person's path through the world seldom changes and even more seldom will it change abruptly. And the shape of your path was visible from the beginning" (No Country 259).

There are allusions in The Counselor suggesting that the twenty-first century has led us further down the spiral, normalizing what Elmore and Elmore called the "flat anthropology of neoliberalism [which] depends upon the inevitability of human nature" (182). This article will apply a similar logic to The Counselor, proposing it as a critique of a more complete neoliberal modernity, and the increasingly routine fixture of neoliberal logic through the spirit of entrepreneurship, which erodes the integrity of law (an enterprise supposedly represented by the protagonist) by marketizing its output. Jacques Derrida reminds us that law is the human pursuit of justice, and thus open to manipulation by forces that are either averse to the true dispersion of an undeconstructible conception of justice, or reminiscent of a site of "originary violence," out of which some sense of order emerged. ${ }^{2}$ For James Dorson, Judge Holden is a reminder of this void, maintaining a constant presence and influence upon human affairs with lucid rhetoric. Holden is evocative of an association between the corruption of capital, an imposition of power and marginalization, and the oratory eloquence of law as an enterprise obscuring routes to equity of representation. It is worth recalling Holden's pronouncement regarding the competing dynamics of moralism, entitlement, and might: "Moral law is an invention of mankind for the disenfranchisement of the powerful in favor of the weak. Historical law subverts it at every turn" (263). This can be equated to Walter Benjamin's distinction between "positive" and "natural" law. ${ }^{3}$ Holden purports the latter to be persistently subversive of more contingent, fragile matters of justice. Malkina assumes Holden's legacy in The Counselor, and not unlike Anton Chigurh, is representative of a neoliberal outlook, which "was from the very beginning a project to achieve the restoration of class power" (Harvey, Neoliberalism 16). The Counselor echoes and furthers this process, stemming from the contemporaneous systemic remnants of such an unjust or power-oriented order, made tangible by observing closely the devices through which exploitative economies exist, expand, and thrive. Westray, for example, assures the Counselor that by "follow[ing] the money" he will see that the cartels are quite unambiguous in their motivations - "The beheadings and the mutilations? That's just business. You have to keep up appearances. It's not like there's some smoldering rage at the bottom of it" (58-64). The evocation of primordial chaos is telling in its reminder of such forces, or their resemblance in modern economies of desire and consumption-these are not purely 
criminal, but are rather tethered directly into the grand maelstrom of globalized capital. This entanglement, with Malkina acting as its symbolic agent, ultimately shapes the narrative arc of tragic circumstance.

\section{Digital Capitalism, the Global Frontier Ethic, and Gothic Capital}

Dan Schiller, at the turn of the millennium, set about debunking the prophetic promise that the internet, with its capacity for positive deterritorialization, would lead us to "global brotherhood" and increased democratic consensus beyond the trappings of insular nationalisms (xiii). He states that "[t]his utopian vision-Internet as salvationexpresses ancient yearnings. Historical detoxification through scientific knowledge: the truth- information?-will make us free" (xiii). His assertion that "the Internet comprises nothing less than the central production and control apparatus of an increasingly supranational market system" (xiv) is now more obvious, and as such, I argue, it facilitates a global frontier ethic McCarthy capitalizes upon in The Counselor.

5 Expanding on the process of corporatized globalization through cyberspace, Luis Suarez-Villa asserts that the increasingly technologized movement of capital "is grounded on the premise that technology is neither completely 'neutral' in a purely functional sense, nor is it wholly 'cultural' as a sociocultural force unto itself. Technology is a result of human actions and decisions. These decisions have social, political, and economic dimensions, and are therefore not purely technical or indifferent to society" (Technocapitalism 3). It is this observation, which pertains to the project of expansion, its discontents, and displacements McCarthy renders in his articulation of the American South under modernization-specifically in the Border Trilogy (1992-1998). Dorson's application of Walter Benjamin's thesis regarding the dualism of modernity and barbarism is surely correct in this respect, and I argue that The Counselor expands on this reading of McCarthy as digi-capital takes on an even more gothic potentiality in the twenty-first century. If The Road (2006) is a tale of America in a land after clock-time, then The Counselor-despite its concessions to cinematic grandeur and simplicity of narrative ${ }^{4}-$ does continue this implicit critique of the current sociocultural dilemmas under what Mark Fisher calls "capitalist realism." The culture of stagnation, which Fisher locates in products of the early twenty-first century like Children of Men (2006), is equally as applicable to McCarthy's postmodern awareness, and David Holloway's 2002 monograph on McCarthy, The Late Modernism of Cormac McCarthy, has done much to enlighten us as to the conscious presence of this style in the writer's oeuvre.

6 Cities of the Plain (1998)-originally conceived as a screenplay in the 1980s-leaves its protagonist in the midst of an alienated existence, an America not fully recognizable to the young Billy Parham in the previous novels of the Border Trilogy. The industrialized world encountered by John Grady as he bears down on the close of a century remains unshaped and equally unknowable. One is imbued with the sense that, despite all technological advancements, our species will not surmount the inherent folly when attempting to completely rationalize the "immappable world of our journey" (Cities 290). Markers of progress will remain beholden to such prehistoric entities as "[a] pass in the mountains. A bloodstained stone. The marks of steel upon it. Names carved in the corrosible lime among stone fishes and ancient shells. Things dim and dimming. 
The dry sea floor. The tools of migrant hunters. The dreams enchased upon the blades of them" (Cities 290). Matters of orienting our progress through mechanization and rational logic are continually complicated by McCarthy-quite often by metaphysical narratives competing with secular primacy in their depth of rhetoric, as Ciarán Dowd notes with specific focus on The Sunset Limited (2006). ${ }^{5}$ Similarly, Steven Frye suggests that McCarthy has always placed "emphasis on the unanswerable," tying him to a tradition of American gothic romance erring toward "radical skepticism, the notion that there are boundaries to the human intellect, realms beyond which the human mind cannot travel" (12). The contradictory logic of Enlightenment progress, as it meets and contends with such skepticism and darkness perpetuates itself further in The Counselor, I argue, by an implicit counter-narrative taking place-the respectability of the protagonist's career is portrayed as something essentially linked to the subcultural criminality forming a specter of disruptive influence on the surface economy of supposedly ethical legitimacy. A seamless flow of capital exists between them, such that both are bound up in one barbarous enterprise, emboldened by impersonalized transactions and eventually Malkina's fusing of digi-commerce and domination through capital-an extension of naturalist hierarchies. The Counselor, I suggest, attempts to make the spectral human costs of upward social mobility (and the consumable markers of its attainment) visible-this intention of ethical action is ultimately stymied by Malkina's logic of domination and facilitated by the intangibility of her illicit capital acquisition.

7 The conditions of neoliberal capitalism allow for a timely metaphorization making visible the antinomies of commodity-fetishist postmodernity. That which exists in the realm of such economies of desire north of the American border is entrenched in all of its bourgeois trappings; Reiner, for example, entices the protagonist into an investment opportunity centering on a venue for urban socialites. This venture operates as a tangible arena and prism through which the animating dramatics of a large scale narcotics deal mask the dark potentialities and realities of its human cost-hence I argue that the journey or transit undertaken which acts as a counter-narrative to the protagonist's legitimate career and lifestyle serves to symbolize the suppressed violence in cross-border commodity exchange. The apparent opposite of ethical commerce is situated in the very core of its enterprise-what is more, it arises directly from entrepreneurship. The viewer or reader bears witness to rather typical McCarthian bloodshed; its terminal purpose is the deliverance of a commodity narcotic, which in itself signals an unusual form of class-oriented discourse. The chief product of such enterprise is likely to be an opioid, or something of high market value like cocaine -this substance has a longstanding vernacular and clinical association with privilege, as opposed to the denigrating effects of other competing substances. Ronald Siegel, for example, associates it with "the privileged class" (37), while David Banash has interrogated its association with jadedness and squandered opportunity in middle-class narratives of late twentieth century and early twenty-first century film-Traffic (2000), The Basketball Diaries (1995), and Requiem for a Dream (2000) illustrate this. McCarthy offers a relatively unique narrative in this respect, as the commoditized drug market is not treated purely as an indulgence at point of purchase to the affluent inhabitants in the establishment his protagonist will operate with Westray, but rather focuses on the labor involved in its production and transit-a nuance noticeably lacking in recent American fiction. It is this focus upon work, production, and its effect on the intermediary (contingent) practitioners in a cross-border dynamic which shifts the 
primary actors and perspective from consumer to worker. This focus makes The Counselor a productive addition to McCarthy's literary output, and indeed the literature (or cinematic depiction) of communities defined by the sociocultural economies embroiled both directly and tangentially in narcotic consumption ${ }^{6}$. In terms of American literature this act of ethical imagination, of cynically representing the role of the global entrepreneur as something implicated in a sub-economy feeding off the routinely disenfranchised class who are-by their nature and circumstance-traffickers as opposed to consumers, I argue, makes The Counselor worthy of inclusion and attention. It both invites a critique of the continuing relevance surrounding class conscious politics in the U.S.-Mexico borderlands, and the conditions of neoliberal modernity confounding such efforts of representation and articulation.

8 The Counselor, like many of McCarthy's protagonists, acts as a liminal figure who travels between the U.S. and Mexico. This produces two noticeable outcomes: first, it highlights the privilege of white American identity in the racialized hierarchy. One must only recall Llewelyn Moss's repatriation in No Country for Old Men (2005) by asserting his right to pass northwards through the border because of his status as a military veteran, while the cost to others is a seemingly invisible violence-illegitimate in the eyes of the regulatory framework controlling those in transit. This naturally produces the second circumstance, that of a spectral economy at work in matters concerning production, consumption, and transit-both in terms of material entities, and the obvious allusion to the marketability of human bodies as product when the operation of transit is reversed, from South to North. When the Counselor meets Westray-initiating the double-bind of law figure and transgressor (legitimated by class discourse)-their conversation illuminates the obfuscation of commercial product value as it travels from Columbia, through Mexico, and finally across the border to Texas and further north toward Chicago. Deciding upon the mitigating factors, the Counselor asks what net value his share in the proposed narcotics deal could fetch: “Westray: Hard to put a cold dollar on it. You don't know what your expenses are until it's actually delivered. It's six hundred and twenty-five kilos. Pure uncut. It sells for about fifty bucks an ounce in Columbia and the street price in Dallas can be as high as two grand" (53).

9 The added value of such a transaction implied here is risk, alongside a natural McCarthian theme-the violence endured in transit, reminiscent of the barbarous economy of scalps in Blood Meridian. What is of primary interest here is the prism through which such a transaction, in fiscal terms, transcends pure criminality and is washed clean in the anonymity of raw capital. Westray explains:

You've got the money guys. You have to get cash in dollars into Mexico and then they have to get it out again. That's all they do. You have to use US banks. This means you have to have a corporation. And to do that you have to have someone on the inside. You'd be surprised at the people who are in this business. (54)

10 Suarez-Villa makes an incisive point on the shift from industrial capitalist modes of production and trade to a more ethereal digital currency by citing the commoditization of more incorporeal entities and substances: "The tangible resources of industrial capitalism, in the form of raw materials, production hardware, capital, and physical labor routines are thus replaced by intangibles" (Technocapitalism 4). The result being a further reduction in the possibility of emancipation through technology or technologization. He elaborates on the condition as such: 
The dominant influence that corporatism exerts over technological agendas today, in its quest for power and profit, implicitly invalidates the purely functionalist view of technology. The culturalist view, which assumes that technology is a system unto itself from which there is no escape as society is molded and controlled by technological forces, also seems unsuited to any consideration of an emancipative role for technology. From the culturalist perspective, attempting social interventions is pointless since there is no way to oppose technological forces, except to retreat to the primitive or the metaphysical. (4)

11 This retreat to "the primitive" and "the metaphysical" is evocative of the bind McCarthy's protagonists have readily found themselves in, both culturally and socially -the Border Trilogy sees urban modernity extinguish a pre-industrial, agrarian mode of life for its characters. In this reading of The Counselor, I propose that McCarthy is attuned to the conditions of twenty-first century existence that have seen corporatization advance at a ferocious pace. If Anton Chigurh can be understood as the figure of neoliberal capital in No Country for Old Men (2005), with often quiet yet merciless violence-seemingly dissolving the border structure as a backdrop of 1980s Reaganomics-then the Counselor is a logical outgrowth of the internally contradicted figure of twenty-first century Homo Economicus, though his transgressions have been banalized through the ideological dominance of the economic structure.

The protagonist is at once compelled to participate in the economy's dark foil-which, as we have established, is not so much the opposite of a functioning marketplace for McCarthy, as its villainous co-conspirator-and also become its victim. Not only this, but Laura (soon to marry the Counselor) is rendered an expendable cost in its standard operation. She becomes an element of human capital, subsumed into a subjugating and transgressive economy the Counselor is made aware of, and is yet enthralled by. What is more, this practice appears normalized, and the connection between femicide, narcotics, and capital is articulated by Westray prior to the protagonist's agreed participation in the central narcotic shipment, which they will manage at a remove, evoking a critique of managerial distance, and the contingency of a subordinate class. Westray explains their venture into the passage of such substances in the lexicon of entrepreneurial self-interest. The Counselor will pursue his ascent in a bourgeois social hierarchy by entering into its shared marketplace of illicit capital-which will soon fuel his socially acceptable venture (a night-club) in Texas through demand for the product in fueling middle-class leisure activities (likened to primitive hedonism), with little regard for the human cost. Westray suggests that the movement of drugs is merely a transition from more insidious practices of the recent past:

Westray:... Before the so-called drug wars who do you think was killing all those young girls in Juarez?

Counselor: I dont know. Nobody knows.

...

Westray: Come on, Counselor. Hundreds of young girls? Thousands, most likely. Follow the money. If you have so much cash that you're using it to insulate your house and you've bought all the cars and clothes and guns that you can find a place to put, and you are morally depraved beyond all human recognition, what then do you spend your money on?

Counselor: Why do they kill them?

Westray: Who knows. For fun. Snuff films. You'll see. Those will start turning up.

(58-59)

13 The implication, of course, is that Laura will shortly become the subject of one of these frightening productions. ${ }^{7}$ Exchange value thus finds its familiar trope of reference with 
human capital and this has a degree of precedent in McCarthy's work. Blood Meridian suggests that the pursuit of cultural and fiscal supremacy is secured through scalp hunting. Furthermore, the earlier novel's epilogue ${ }^{8}$ suggests this connection is not American, so much as human, and the emergence of a globalized, universal system of neoliberal commerce facilitated (at least in part) by digital technology is thus a seemingly natural entity. Malkina's thirst for domination in such an order of human affairs-alongside an ability to attract and ensnare new parties with the promise of liberation through fiscal and operational cunning-befits her ready association with the natural or wild environment and the sense of fated determinacy for all who participate, by overt will or coercion (though this is ultimately a false dichotomy). She is emblematic of a paradox in free market exchange ideology, and its ability to allocate resources in a more equitable fashion than enforced trading principles-her final iteration in the text is evocative of this: "Should we think about ordering? I'm famished" (184). She initiates an exchange for sustenance in a "penthouse restaurant" in a nondescript "world city" (176), suitably ending the narrative having maintained existing social hierarchies. Her statement is illustrative of both continued avarice and an unchallenged ability to order, in a literal and conceptual sense. The Counselor, accordingly, consolidates a fusion of capital, dominance, and violence, and adds to its fluidity and boundless remit in an era of global capitalism enabled further by technocommerce. The latter feeds the illusion of naturalness in free-market ideology and its protection of existing hierarchies, while making it increasingly difficult to imagine an emancipatory circumstance or rhetoric to challenge it.

\section{Neoliberalism, the Global Frontier Ethic, and the Mechanics of Post-Industrialization}

Definitions of neoliberalism, neoliberal capital, and the culture stemming from it (or rather, its impact upon the cultures and identities it affects) vary, but David Harvey's still remains foundational and constant:

Neoliberalism is in the first instance a theory of political economic practices that proposes that human well-being can best be advanced by liberating individual entrepreneurial freedoms and skills within an institutional framework characterized by strong private property rights, free markets, and free trade. The role of the state is to create and preserve an institutional framework appropriate to such practices. The state has to guarantee, for example, the quality and integrity of money. It must also set up those military, defence, police, and legal structures and functions required to secure private property rights and to guarantee, by force if need be, the proper functioning of markets. Furthermore, if markets do not exist... then they must be created, by state action if necessary. (Neoliberalism 2)

In Social Justice and the City (1973), he began his critical theorization against Henri Lefebvre, who suggested that urban living could present an opportunity to live over and against the demands of capitalism. Harvey disagreed, suggesting that modern urbanity was more likely to represent the apotheosis of how capital could organize us, dictate space, and how human beings orientate themselves (socially, culturally, economically, and physically) in relation to one another. It represents the absolute centering of capital as the chief organizing principle of modern society, and is thus the means through which urbanization is brought to those who remain outside modernity. This, for Harvey, among others, presents a false promise of inclusion. Thus, when a 
narrative of late capitalism, or perhaps (post) postmodernity is voiced from the perspective of an entrepreneur like the Counselor, and other similarly oriented characters like Westray and Reiner, a neo-frontier ethic becomes quite visible. In fact, working from Harvey's definition, the term "human capital" becomes something else altogether in the context of McCarthy, and extends the gruesome metaphor of Blood Meridian even further-humans become capital. Such a system of exchange value is not so much adopted, but rather imposed, specifically from one dominant culture to another, in order to fortify a neo-imperialistic stance that is more tacit in appearance, and thus seemingly more palatable. This description further clarifies Malkina's symbolic association with the ideology outlined above.

By now, readings of McCarthy as a chronicler of industrialization are well established (Holloway and Dorson, mentioned above, for example). Craftsmanship and the implements of labor are often apparent as corollary devices that reflect an expert practitioner's remit within an economy, but also serve as modes of violently interrupting the civilized flow of ideology. They mark a precise rupture in the process of concept-design-manufacture-sale-use-expire symbolizing a functioning, logical economy of consumption, agency, and equitable justice. The latter is a problematic entity for McCarthy, and Dorson draws upon Derrida's concept of "originary violence" to great effect in explaining the specter of violence surrounding human commerce, regardless of its distance (temporal or otherwise) from primitive trade and law, or the lack of it.

17 Certain implements in McCarthy's previous work bear a weight of intrigue for criticsAmy Hungerford (87-92) offers a particularly notable interpretation of Lester Ballard's encounter with a blacksmith, wherein the craftsman refuses monetary compensation for the trade. Similarly, Brown's imposition on a farrier in Blood Meridian sees his offer of coins refused on the basis that there is no rational reason "anybody [would] want to cut the barrels off a gun like this" (280). Its presentation in a "polished mahogany case with a brass nameplate bradded to the lid" apparently furnishes the item with a value beyond mere commerce (279). These items of course are also implements of violence; they act as a concise fulcrum or focus point, whereupon agents of their use can enact the dualistic impositions of an apparently civilized societal model. Each item is treated with such reverence by those who are capable of making or maintaining it (evoking a Marxian interpretation of alternative value systems) that they remind the agent of their responsibility, and thus of a capacity to choose. If Chigurh's coin can be counted among these items, then choice can be deemed secondary to fate, and under postindustrial conditions the idea of agency and an ability to enact a will (purely good or evil) is lessened. ${ }^{9}$ For McCarthy, the products of labor appear to leave some mark of their designer, and also of the system they are designed to perpetuate-The Counselor continues this trend with the inclusion of a seemingly fictional device referred to as a bolito. Reiner explains the unlikelihood of the Counselor escaping this way of life once he transgresses from law to criminality; the cartels, he suggests, will likely "set up shop across the street" if this innovative scheme in cross-border narcotics transport comes to fruition undetected (54). The transgressive trade is thus marketized, and works on a parallel logic to the legitimate surface economy-with the Counselor now trading upon the liminal ground between them, or perhaps highlighting their interdependency. Reiner asserts their method of dispatching competitors by using a bolito:

[I]t's a mechanical device. It had this small electric motor with this rather incredible compound gear that retrieves a steel cable. Battery-driven. The cable is made out of some unholy alloy, almost impossible to cut it, and it's in a loop, and 
you come up behind the guy and drop it over his head and pull the free end of the cable tight and walk away. No one ever sees you. Pulling the cable activates the motor and the noose starts to tighten and it continues to tighten until it goes to zero... Mostly wretched excess of course. It's just that there'd be no easy way to turn the thing off. Or reason to. It just keeps running until the noose closes completely and then it self-destructs.... The wire cuts through the carotid arteries and sprays blood all over the spectators and then everybody gets to go home. (3637)

This method of decapitation-a theme resonating through much of McCarthy's articulation of trade from Blood Meridian onwards-is grotesque, but also notable in its advancements on previous iterations. It is, first and foremost, a fictional device-a creation of McCarthy's, but I would argue that it symbolizes and extends the metaphor of Darwinian capitalism outwards from jingoistic westward manifest destiny into a more impersonal structure. The Counselor muses on the nomenclature briefly: "A bolo is one of those skinny neckties. Or is it one of those things you throw? Argentina" (35; my italics). After a reference to formal working attire, the association is made with a type of knife, or machete, used variously in Central and Southern America, along with Cuba-often called a cane sword when deployed in agriculture, and regularly finds a use in transgressive (violent) behavior. Dismemberment from such an implement is remarked upon elsewhere in the text (Westray's description of snuff films), but the more brutal and dramatic violence it inflicts is symbolic of a connection to something more primordial for McCarthy here. The bolito maintains the aura of previous instruments-the axe (Child of God) and shotgun (Blood Meridian)-but stands as an implement exclusively engineered for violence. It is depersonalized, in that it does not need wielding, or mastery-moral choice of purpose is negated, and consequently the transition to an altogether more ominous industrialized modernity is completed. The tools servicing such an economy represent a sense of bleak completion, or utter domination by what Fisher called "gothic capital" (15). This proposition encompasses the paradox of efficiency, dark potentiality, and sometimes vicious teleology of liberal capitalism, with various mechanics and implements of labor doubling as tools of increasingly impersonal systemic ferocity. It is hyper-violent, with McCarthy's description cascading into near-cartoon horror, as opposed to the more menacing precision of violence inflicted by Judge Holden or Anton Chigurh (a device for dispatching cattle with minimum suffering is evocative of such a contrast) for example. Therefore, in McCarthy's rendering of modernity, one's fate is very much determined by capital and one's interaction with it (quite literally, in the case of Chigurh's coin in No Country for Old Men).

19 Temporal advancement, consequently, leads his protagonists to a reality described best by Theodor Adorno and Max Horkheimer in their Dialectic of Enlightenment (1944)choice is somewhat of an illusion, and the only freedom gained is "the freedom to choose what was always the same" (136). An object like the bolito, then, inspires an interpretation of its design and function, but also a moment Walter Benjamin once called a "now of recognisability" (The Arcades Project 426). Benjamin's desire to uncover the layers of political, social, and economic obfuscation remains specifically relevant here, as McCarthy's unusual clarity of expression regarding the implements of work (and their various uses) appears to have reached an apex. The objectivity and submission to choice is present in previous implements, such as an axe, or even an ornate shotgun-both are objects of work, commemoration, sentiment, and perhaps some vague reminiscence of manifest destiny. Their deployment as a method of 
destruction is at the behest of those who wield them, and arguably support an association of work with a socio-economic system of uneven progress. The bolito suggests a point in McCarthy's output representing a now (in Benjamin's sense of the term) of closed potentialities. The design of this machine has a more overt purpose-“It just keeps running until the noose closes completely and then it self-destructs" (37).

\section{Natural Law, Digital Modernity, and the Closing Potential of Moral Action}

20 We can say without speculation that The Counselor serves to further the existing assertions of McCarthy's conscious elucidation of neoliberal realities. It now provides the vocabulary, script, and doomed agency of a new form of determinism-protagonists and associated actors see their gambits (largely attempts to succeed in an innately exploitative ecology) fail, rendering a form of tragedy now normalized in the structure of feeling McCarthy's literary ventures routinely exhibit. A new sense of determinism is reified and perpetuated by the standard model of Enlightenment virtue-knowledge and inquiry begets liberated individualism, often through the production of technologies that limit human labor. The bolito is disconcerting in its ability to automatically complete the task that was previously the domain of rugged individual agency (often tethered to masculinity) in the guise of Judge Holden and Anton Chigurh. The Counselor is thus unique in McCarthy's body of work in that it explores a paradoxical lack of identifiable accountability at the heart of post-FIAT politicoeconomic regimes, and the use of new technologies to create this strange set of circumstances. The modern citizen is-we are led to believe-empowered or buoyed by one's extended privilege of property rights and right to pursue self-interest, leading to an erosion of the state as a social protection provider, in favor of an entity guaranteeing rights to increased privatization. In theory, this would amount to a greater level of responsibility, but in truth, the crisis in global capitalism since 2008 has made visible the inadequacy of this philosophy on a mass scale. It is the anonymity of capital as it is empowered in terms of protection, ease of movement tied to increased digitization, and ultimately decreased socialization of the resources it portends to represent, that receives explicit attention by McCarthy here.

Malkina is symbolic of natural law which imposes a Darwinian logic upon suffering, along with social, political, and economic hierarchies among various populations. Previously, McCarthy's texts have focused upon the interchange between North America and Mexico. The exploitative relationship, drama of uneven development, and naturalization of the kind of hierarchies legitimating such a state of affairs has provided McCarthy with an enduring motif of cross-border trade at least since the publication of Blood Meridian. The conditions of Chigurh's brutish yet precise impositions on previously essentialist borders, however, signaled a change in the presentation of trade relations and the movement of capital in the late twentieth century under the regime of Reaganomics. I would argue that The Counselor extends this metaphor even further through an increasingly anonymized presentation of capitalthat is to say, identities receive protection above and in spite of misdemeanors such resources represent-and much of this is attributed to automated and digitized conceptions of modernity. The former is represented by the bolito, and the latter is signaled by the nature of Malkina's ultimate trade. Her conversation with a computer 
engineer in a "world city" lends itself to the liquidity of capital as it is represented here -Chigurh's coin is no longer a viable metaphor, as the substance of money is now represented more properly in "machine readable code" (169). Reminiscent of Holden's erudition concerning more ancient crafts, Malkina demonstrates superior fluidity and an almost natural lexicon in digi-commerce and information technology, dismissing VPNs and routers as insufficient to the needs of her nefarious transaction. She explains the details of a transactional interception (with Westray as victim) by way of remote digital access to her tech-savvy interlocutor: "You can have a basic toolkit with Sequel servers and whatever, but a Remote Access Trojan Horse like Zrizbi or Torig is not for keeping track of your household expenses" (170). The ultimate benefit of these means is "[i]t's not traceable" (170).

When the topic of law enforcement enters the conversation, Malkina is quick to dismiss the possibility of accountability further:

I'm not worried about that. What's out there is out there. They think their traffic analysis is sophisticated but by definition it has to lag the protocols that generate it. As for the physical computers, you put them in the oven, set it to four-fifty and walk away. Or just pour thermite on them. I can download everything I need to take with me onto a USB stick. (172)

The culmination of her scheme sees Westray beheaded, by employing a bolito serving as an ersatz remote or automated executioner, and distraction-he is beheaded in a very public and gruesome manner, "[h]is left carotid artery bursts and bright red blood sprays in a fountain into the air and splashes back on the sidewalk" (166). It is appropriate to employ Fisher's assertion here:

To reclaim a real political agency means first of all accepting our insertion at the level of desire in the remorseless meat-grinder of Capital. What is being disavowed in the abjection of evil and ignorance onto fantasmatic Others is our own complicity in planetary networks of oppression. What needs to be kept in mind is both that capitalism is a hyper-abstract impersonal structure and that it would be nothing without our co-operation. The most Gothic description of Capital is also the most accurate. (15)

Westray's execution is a functional symbol of the latter in its grotesquery and spectacle, and expands the narrative metaphor of commerce that has been explored by Elmore and Elmore, and more recently by Dorson, who expresses the suitability of Benjamin's contention that modernity is intrinsically tied to barbarism. He pays particular attention to the following passage from Blood Meridian, proposing its resonance with the cold eye of calculability employed by Holden in his dominance, and an emergent power of gothic capital: "It is this false moneyer with his gravers and burins who seeks favor with the judge and he is at contriving from cold slag brute in the crucible a face that will pass, an image that will render this residual specie current in the markets where men barter" (Blood Meridian 310).

Dorson avers that "[i]n contrast to the promise of regeneration through violence, the violent instatement of law in Blood Meridian does not mark an end to violence, but is a promise of more to come, even if that violence is now legitimated by the new order" (167). The Counselor, stemming from the metaphor of natural law finding a voice through Malkina's proximity and affinity to numerous predatory non-human entities, ${ }^{10}$ both reinforces and articulates the ominous growth of the these markets across a new global frontier. This, I argue, is facilitated by the conditions Suarez-Villa describes as "technocapitalism," which sees corporatism enabled through various factors in digital 
modernity. The means of Malkina's rogue agency resemble those of the modern hacker, and her proficiency in this regard is an updated version of Holden's mastery across an expansive array of traditions, media, and skill-sets. Her familiarity with the diamond trade provides a link to a more familiar commerce between the exchange value of an item, and its cost in the realms of labor relations, traditions, unseen violence, and the power of commodities or symbolic status to shield a consumer from barbaric realities. A duality emerges here with the protagonist's simultaneous enterprise-law and criminality-and the attraction to the product of narcotics, the fuel of middle-class sociability, soon to be housed in a venue he will also invest in.

The new and updated class politics of neoliberalism is visible, but it is not merely an attenuation to expectations of high-budget screenwriting. Rather, I suggest, The Counselor is equally deserving of what Dorson has deemed McCarthy's propensity for the presentation of "counternarratives." There is a duality, he suggests, to much of McCarthy's prose that represent, parody, and critique ideological structures and associated value systems from within. The counselor too, based on the above exploration, performs this duty, rendering a tragedy within the trappings of digital modernity-the increasingly anonymized and impersonal nature of transactions and commerce can be seen, along with an extension of the frontier ethic to a global sphere of finance capital, enabled and facilitated by the technology that has always served a dual purpose of representing wealth acquisition and brutal inhumanity. Messianic promise, however, is an equally visible and problematic theme in McCarthy's later prose. Does such an ordering system, mirroring the frontier ethic, expansionism, subjugation, and flawed justice it evokes, present an alternative to the reader or viewer in a similar manner to the child of The Road?

In Capitalist Realism, Fisher's celebrated articulation of the apparent dominance of neoliberal cultural logic, he asserts that "emancipatory politics must always destroy the appearance of a 'natural order,' must reveal what is presented as necessary and inevitable to be a mere contingency, just as it must make what was previously deemed to be impossible seem attainable" (17). This sentiment espouses a tangible alternative or method of opposition to the conditions of McCarthy's utterance of twenty-first century global capitalism. The protagonist is a symbol of an ordering system of law, but one rendered inherently flawed, insofar as it is equated within the realm of business. The question we are left with is thus: does McCarthy's account of a human drama under capitalist realism, ensuring the opacity of unethical human relations (mainly centered upon commodity fetishism and its spectral violence), modes of consumption (a drug trade fueled by largely middle-class desire enabled by an invisible human cost), and uneven development, allow us to envision emancipation-that is, the promise of liberation? Elmore and Elmore claim that McCarthy's philosophy of history, somewhat postmodern in its weakening of temporal structures, represents a method of resistance:

If human nature has always been competitive, then the current neoliberal structure of society is nothing but the expression of that human nature. However, by placing the past before the present, out in front of us in the dark, the novel concludes by questioning our understanding and relationship to our own cultural, social, and anthropological history, a questioning that strikes at the very heart of neoliberalism's claims to naturalness and inevitability. (182)

Sheriff Tom Bell in No Country for Old Men stands among the last of a generation whose passing will initiate the totalizing of such a historical logic-humankind has always been competitive, and thus neoliberalism is merely the natural order of things. The 
Counselor's journey from an agent of what Benjamin called "positive law" to a criminal existence-though it becomes more difficult to tell the difference under an increasingly materialist mode of self-generation and social capital-seems to represent a further imposition of totalizing market logic into narrative form. The text and accompanying cinematic rendition, consequently, imposes both the need for some redemptive logic, alongside the increasing lack of availability for it. Westray humorously suggests this by eliciting the following: "You know why Jesus wasn't born in Mexico dont you?... They couldnt find three wise men or a virgin" (63). Furthermore, he proposes that the most apt description of Mexico lies in the realm of the grotesque. This would certainly account for the existence of snuff films. Their presence in the narrative, tenders a fictional response to a genuine site of trauma in the U.S.-Mexico borderland region, culture, and memory-the Juarez Femicides ${ }^{11}$-and Laura's eventual consumption by such a monstrous enterprise, amounts to a commentary on media purporting to represent the absurdity of a collective omerta or tacit agreement with such brutality on the part of the average commodity consumer. Romanticizations of the terrifying inequality, and cooperative grim interdependency of cross-border economies construct and perpetuate these systems of dialectical violence/supply.

A grim premonition is exhibited by Westray-if such media depicting gratuitous violence and suffering does exist, it would serve to reflect the true ferocity endured by subaltern communities and people. Their increasingly marginalized circumstancessupported by the fact that the fate of victims is shrouded in mythology, making the reality of the situation inherently obfuscated-invite a comment upon McCarthy's stance on representation, and how such social inadequacies and depravity are to be understood beyond the veneer of progress imbued by technologized modernity as he renders it. Hillier (2017) asserts that McCarthy's late writing, up to and including The Counselor, veers ever closer to the genre of fable-a tale that is "didactic and fiercely moralistic" (162). The "ethical entropy" visible in these later narratives, for Hillier, invites resistance from the reader to similar conditions they endure, thus rendering McCarthy a moralist (166). My understanding of The Counselor runs contrary to this, however, in that I believe the story incites rumination on the difficulty of moral action when faced with the confounding logic of neoliberal modernity in all that it represents -a global system of commerce paradoxically extending rights of privatization while also making the currency of its worth more opaque. The "ethical entropy" Hillier correctly denotes as an identifiable characteristic lends itself, I argue, to a tragic consciousness that is actually furthered by the author's narrativization of twenty-first century globalism. The precariousness and contingency of individuals serves to limit the grounds for and ability to imagine concrete positive moral action, and it is this conundrum that makes the fable somewhat stultified as a model of storytelling-the only relevance of it in this reading is a reminder of its troubling yet impending redundancy. The errors and difficulties of comprehending such an ephemeral system of human organization become the defining feature of the tragedies the reader/viewer bear witness to.

Above I have argued that The Counselor provides a lucid articulation of neoliberal modernity, building upon the realities theorized by Elmore and Elmore in relation to No Country for Old Men, when Homo Economicus was a protean yet nascent figure. The Counselor presents implicit, paradoxical, yet natural horrors in the everyday reality of consumer etiquette, and class-oriented status of twenty-first century urbanite 
experience-classing the narrative as a functional critique of liberal modernity, with added emphasis on the enabling promise of digital globalism. The tenor of McCarthy's representation, I suggest, is best understood through the ominous permutations of Fisher's concept of "capitalist realism." Consequently, I propose that the appearance of digi-commerce and technocapital is a new yet timely inclusion in McCarthy's frame of reference. Its effect is a further obfuscation of the true or real cost of a system of global capital that, as Fisher asserted, is a "hyper-abstract impersonal structure" (15). Our inability to grasp it, despite our unyielding participation in it-as though it were a feature of natural or organically occurring competition (symbolized by Malkina)-is eventually presented as a deeply problematic state of affairs. McCarthy's narrative, I propose, does not provide any simple paths to emancipatory moral action, but rather alerts us to the continually fraught duality of modernity and barbarism. Rather than uncouple them, increasingly complex mechanisms of distraction and hedonistic habits deflect our collective recognition of its reality and our unrelenting participationviewed through the dialectical lens of drug culture, corporatism, and mechanisms of social class creation. Accordingly, The Counselor might not be such a departure from The Road, and is similarly keen to remind the consumer of the emancipatory potentialities of more grounded, socially engaged interpersonal relationships, the kind that recede from view and are continually disrupted by the trappings of digitally empowered modernity.

\section{BIBLIOGRAPHY}

Adorno, Theodor, and Max Horkheimer. Dialectic of Enlightenment: Philosophical Fragments. Trans. Edmund Jephcott. Verso Books, 2016. Print.

Banash, David. "Intoxicating Class: Cocaine at the Multiplex." Postmodern Culture 12.1 (2001): n. pag. Print.

Benjamin, Walter. The Arcades Project. Trans. Howard Eiland. Cambridge, MA: Harvard UP, 2002. Print.

---. “Critique of Violence." Reflections: Essays, Aphorisms, Autobiographical Writings. Trans. Edmund Jephcott. New York: Random House, 1995. 277-300. Print.

Cooper, Lydia R. No More Heroes: Narrative Perspective and Morality in Cormac McCarthy. Baton Rouge: Louisiana State UP, 2011. Print.

Derrida, Jacques. "Force of Law: The 'Mystical Foundation of Authority." Deconstruction and the Possibility of Justice. Eds. Drucilla Cornell, Michel Rosenfeld and David Gray Carlson. New York: Routledge, 1992. 3-67. Print.

Dorson, James. Counternarrative Possibilities: Virgin Land, Homeland, and Cormac McCarthy's Westerns. Frankfurt am Main: Campus Verlag GmbH, 2016. Print. 
Dowd, Ciarán. “'A Novel in Dramatic Form': Metaphysical Tension in The Sunset Limited.” Intertextual and Interdisciplinary Approaches to Cormac McCarthy: Borders and Crossings. Ed. Nicholas Monk. New York: Routledge, 2012. 112-120. Print.

Elmore, Jonathan, and Rick Elmore. "Neoliberalism, Anthropology, and Human Possibilities in No Country for Old Men.” The Cormac McCarthy Journal 14.2 (2016): 168-185. Print.

Fisher, Mark. Capitalist Realism: Is There No Alternative? Winchester: Zero Books, 2009. Print. Frye, Steven, ed. The Cambridge Companion to Cormac McCarthy. New York: Cambridge UP, 2013. Print.

---. Understanding Cormac McCarthy. Columbia, SC: South Carolina UP, 2011. Print.

Gibbs, Alan. “'Things Happen to You They Happen': Cormac McCarthy and the New Naturalism.” Crossroads and Transgressions: Cormac McCarthy Between Worlds: An International Conference. John F. Kennedy Institute for North American Studies, Freie Universität Berlin, July 7, 2016. Unpublished Conference Paper.

Harvey, David. A Brief History of Neoliberalism. 2005. Oxford: Oxford UP, 2007. Print.

---. Social Justice and the City. Baltimore, MD: Johns Hopkins UP, 1973. Print.

Hillier, Russell M. Morality in Cormac McCarthy's Fiction: Souls at Hazard. New York: Palgrave Macmillan, 2017. Print.

Holloway, David. The Late Modernism of Cormac McCarthy. Westport, CT: Greenwood Press, 2002. Print.

Hungerford, Amy. Postmodern Belief: American Literature and Religion since 1960. Princeton, NJ: Princeton UP, 2010. Print.

Knepper, Steven Edward. "The Counselor and Tragic Recognition." The Cormac McCarthy Journal 14.1 (2016): 37-54. Print.

McCarthy, Cormac. Blood Meridian or the Evening Redness in the West. 1985. London: Picador, 2010. Print.

---. Cities of the Plain. London: Picador, 1998. Print.

---. The Counselor. London: Picador, 2013. Print.

---. No Country for Old Men. London: Picador, 2005. Print.

---. The Road. London: Picador, 2006. Print.

---. The Sunset Limited: A Novel in Dramatic Form. London: Picador, 2006. Print.

Schiller, Daniel. Digital Capitalism: Networking the Global Market System. Cambridge, MA: MIT Press, 1999. Print.

Siegel, Ronald K. "Cocaine and the Privileged Class: A Review of Historical and Contemporary Images." Advances in Alcohol \& Substance Abuse 4.2 (1984): 37-49. Print.

Snyder, Phillip, and Delys Snyder. “Modernism, Postmodernism, and Language: McCarthy's Style." The Cambridge Companion to Cormac McCarthy. Ed. Steven Frye. New York: Cambridge UP, 2013. 27-38. Print.

Suarez-Villa, Luis. Technocapitalism: A Critical Perspective on Technological Innovation and Corporatism. Philadelphia, PA: Temple UP, 2009. Print. 
---. "The E-economy and the Rise of Technocapitalism: Networks, Firms, and Transportation." Growth and Change 34.4 (2003): 390-414. Print.

Villar, Oliver, and Drew Cottle. Cocaine, Death Squads, and the War on Terror: U.S. Imperialism and the Class Struggle in Colombia. New York: Monthly Review Press, 2011. Print.

Wright, Melissa W. "Necropolitics, Narcopolitics, and Femicide: Gendered Violence on the Mexico-U.S. Border.” Signs: Journal of Women in Culture and Society, 36.3 (2011): 707-731. Print.

\section{NOTES}

\section{See Schiller (1999).}

2. See Derrida (1992).

3. See Benjamin (1995).

4. Steven Edward Knepper-in one of the first measured critical expositions of The Counselorsuggested that one of the screenplay's primary downfalls could arguably be its derivative nature, particularly where the plot of No Country for Old Men is concerned. He argues that it is merely another Aristotelean tragedy acting on very similar principles.

5. Dowd suggests a "metaphysical tension" at the heart of McCarthy's corpus, reaching an apex in The Sunset Limited.

6. Villar and Cottle have proposed the existence of a "military-industrial narcotics complex" (156). This sees U.S. neo-imperialism operate in tacit or often open agreement with revenue from the drug trade, serving the dual purpose of destabilizing sovereign governments and furthering the legitimacy of aggressive foreign policy and domestic interference in terms of immigrant populations. They assert that " $[t]$ he annual profits from the global dug trade are estimated to be worth between $\$ 300$ and $\$ 500$ billion with an estimated flow of $\$ 250$ billion going directly to U.S. banks each year," and cite Martin Woods, "a former senior anti-money-laundering officer" from Wells Fargo \& Company (a major U.S. financial institution), who explains that it was merely one culprit among many in the elite financial industries "recently found [to be] laundering money for Mexican drug cartels" (157). This, Woods argues, makes New York and London "the world's two biggest laundries of criminal and drug money, and off-shore tax havens. Not the Cayman Islands, not the Isle of Man" (qtd. in Villar and Cottle 157). Reiner makes direct reference to such complicity in his initial meeting with the Counselor, warning him of the dangers of becoming involved with the Cartels. Accordingly, I suggest, McCarthy's narrative makes a concerted effort to reify the workings of such vast networks of global capital, the means of their generation, and complicity of governing authorities. This makes the role of law-maker, assumed by the protagonist, complicit a priori-his autonomy is limited before any deal is initiated, and is merely an agent of an expansive system of exploitative commodity exchange reaching further into the global frontier via corporate collusion.

7. In the closing scenes, the Counselor rests in a Mexican guest-house, when a package is delivered to his room containing a compact disc. Its contents are not shared, but the implication is rather apparent, considering Westray's explanation for the Cartel's tastes in grotesquery.

8. One of Blood Meridian's epigraphs is an excerpt of an article from The Yuma Daily Sun (June 13, 1982) stating the findings of a UC Berkeley academic concerning a 300,000-year-old skull discovered in Ethiopia showing "evidence of having been scalped." The exploitative and murderous economy consequently receives a shape through narrative and allegory in the context of the novel's frontier ethic, and I argue that The Counselor renders its contemporary connotations under hyper-technologized, globalized digi-commerce. 
9. Alan Gibbs proposes a recantation of this mode of thought, suggesting McCarthy to be indicative of a "New Naturalism" at work in twenty-first century American literary production.

10. Her affinity with cheetahs is a persistent feature. This overt symbolism also evokes a marker of dubious class privilege and questionable status-animal skins, equitable to the previous allusions to scalping in Blood Meridian.

11. The Juarez Femicides refer to an exceptional instance of gendered violence, associated with cartel reorganization from the mid-1990s to present. See Wright (2011) for a more expansive exposition.

\section{ABSTRACTS}

This article proposes a reading of The Counselor (2013) as an extrapolation of the frontier ethic animating much of Cormac McCarthy's earlier writing. I will propose that echoes of Blood Meridian (1985), which presented the duality of barbarism and capital, are audible and perpetuated under digital capitalism, a condition encompassing the expansion of increasingly impersonal and anonymized capital under neoliberal socio-economics, empowered by digital globalization. Thus, the screenplay extends classic McCarthian themes, while expanding the remit of critique to class relations in contemporary cross-border, and global consumer economies. The subversive appetites of Western consumerism-focused around commodity fetishism and narcotics-symbolized by characters like Westray, Reiner, and Malkina, render a distinctly modern tragedy enabling a critique of how (and whether) it is possible to represent and oppose such a system of increasing ephemerality and correlative persuasion.

\section{INDEX}

Keywords: Cormac McCarthy, The Counselor, neoliberalism, digital capitalism, ideology

\section{AUTHOR}

\section{DAVID DEACON}

David Deacon is a late stage PhD candidate at University College Dublin, where he is completing his doctoral research on atheism in twenty-first century American fiction. Alongside Cormac McCarthy, other authors like Sikivu Hutchinson, Hugh Nissenson, and Joshua Ferris are explored in order to establish the variety of atheist philosophies and expressions iterated as an antipositivist critique of neoliberal rationalism in post 9/11 literary production. He teaches literature, cultural studies, and academic skills at University College Dublin and BIMM Institute Dublin. Further information can be found here: https://ucd.academia.edu/DavidDeacon 